\title{
Proposta de Elementos Arquiteturais para o Sistema de Gestão de um Espaço Organizativo: Desenvolvimento da economia criativa no Brasil sob o enfoque sistêmico
}

\section{A Proposal for Architectural Elements of Organizational Management System: Development of the creative economy in Brazil under systems approach}

Eliomar Araújo de Lima, Jeuel Bernardes Alves, luis Fernando Ramos Molinaro

\begin{abstract}
The development of the creative economy in Brazil has been revealed as an array of cultural, social and political opportunities unprecedented. This study approach this issue in order to identify the core elements of organizational development model, which play a role of articulation to enable public and private agents, entrepreneurs and creative businesses and culture communities in terms of participation and empowerment. Starting from ethnographic studies in a local ecosystem of creative economy, the findings of this investigation suggest some multidimensional factors for organizational management system structuring.
\end{abstract}

KeYWORDs: creative economy, management model, social network, systems thinking, strategic management. 


\begin{abstract}
Resumo
O desenvolvimento da economia criativa no Brasil vem se revelando como um vetor de oportunidades em nível cultural, social e político sem precedentes. Este estudo se insere nesse contexto com o propósito de identificar os elementos centrais do modelo de desenvolvimento de espaços organizativos em rede, os quais desempenham um papel de articulação para viabilizar a participação e emancipação dos agentes públicos e privados, dos empreendedores e negócios criativos e comunidades e territórios de cultura. Partindo de estudos etnográficos realizados num ecossistema local de economia criativa, os achados da investigação sugerem alguns fatores multidimensionais para estruturação do sistema de gestão organizacional.
\end{abstract}

Palavras-chave: economia criativa, modelo de gestão, rede social, pensamento sistêmico, gestão estratégica.

\title{
Introdução
}

A economia criativa é um dos setores de maior crescimento da economia mundial. Além de ser altamente transformadora em termos de ganhos de geração de renda, criação de emprego e de exportação, a economia criativa também gera valor não monetário que contribui significativamente para a realização das pessoas, o desenvolvimento inclusivo e sustentável (UNESCO, 2013).

A economia criativa pode ser reconhecida atualmente no Brasil como um processo de inovação cultural, política e social sem precedentes. Trata-se de um novo alento para a economia subterrânea, por vezes informal, que dependerá de projetos transversais de política cultural, dadas suas peculiaridades em termos de capilaridade geográfica e penetração socioeconômica.

A economia criativa brasileira terá condições de se desenvolver de modo consistente e adequado à realidade nacional se incorporar na sua conceituação a compreensão da importância da diversidade cultural do país, a percepção da sustentabilidade como fator de desenvolvimento local e regional, a inovação como vetor de desenvolvimento da cultura e das expressões de vanguarda, além da inclusão produtiva como base de uma economia cooperativa e solidária (PSEC, 2011, p.33).

Uma peculiaridade da economia criativa nos paises em desenvolvimento é a sua profunda dependência de sistemas, processos e instituições culturais informais. Nesses países, muitos trabalhadores criativos, incluindo músicos, artesãos, artistas, designers e técnicos, mesmo atuando profissionalmente, encontram-se na economia subterrânea (UNESCO, 2013, p.26).

0 processo de instituição da economia criativa sob á ótica da socialização do conhecimento e do potencial do trabalho imaterial potencializa a tomada de recursos para o auto desenvolvimento sustentável de uma grande parcela da sociedade brasileira (SIERRA, 2013b). 
Um dos importantes desafios para a promoção da economia criativa no Brasil, de modo a preservar a diversidade cultural existente e manter vivo o tropicalismo tópico, está relacionado com o aparecimento emergente de empreendimentos e negócios criativos, tanto individuais como coletivos. No entanto, a mesma pujança não é observada na instituição e organização de espaços organizativos voltados para a promoção e indução do desenvolvimento da economia criativa.

A capacidade de lidar com a gestão dos espaços organizativos de cultura depende em grande medida da articulação política, social e econômica dos entes federados do Estado Brasileiro, incluindo a União, os Estados e os Municípios, consubstanciada pela participação da sociedade civil organizada, entidades privadas, comunidades criativas e territórios culturais envolvidos. A ação integrada desses interlocutores sociais requer uma organização pautada pela participação e emancipação dos agentes da economia criativa de modo a criar espaços sinérgicos para melhor apropriação de conhecimento e sabedoria sociocultural.

É nesse sentido que se pretende contribuir com este trabalho, partindo da discussão dos elementos arquiteturais que contribuem para o processo de desenvolvimento de espaços organizativos em rede, de modo a facilitar o processo decisório. Johnson (2011) assevera que o principal impulso para a busca de informações nas redes de conhecimento organizacionais é dado pelo papel que elas desempenham nos processos decisórios.

\section{ESPAÇOS ORGANIZATIVOS LARANJA}

A ideia principal ao instituir espaços de cultura no Brasil está relacionada com a noção de espaços de reuniões criativas que contribuam para grupos culturais e favoreçam a promoção de equipes de cooperação, redes criativas, iniciativas culturais a partir da cultura de ambientes colaborativos, que a médio e longo prazo contribuam para impulsionar as externalidades positivas em cada região ou território (SIERRA, 2013a).

Dado que a atividade principal da economia criativa depende essencialmente do fator humano, seja como criador, seja como empreendedor, o primeiro desafio é compreender os princípios e conceitos básicos que norteiam os segmentos criativos, para superar a falta de consenso quanto às discussões sobre as terminologias chaves.

Os diferentes rótulos vinculados à economia criativa refletem e correspondem a diferentes posições analíticas e delimitações ideológicas, corroborando com a história do que tem sido estudado por vários estudiosos da área. Cada conjunto de termos, juntamente com seus antecedentes e suas interpretações, instigam o debate de especialistas (UNESCO, 2013, p.19).

Devido a maior parte das publicações e debates sobre economia criativa ser de origem anglo-saxão, um primeiro obstáculo enfrentado no processo de construção conceitual diz respeito à terminologia empregada nesse campo. Traduções livres geram incompreensões semânticas por causa de diferenças culturais (PSEC, 2011). 
Pensando nisso, Restrepo e Márquez (2013) ${ }^{1}$ adotaram o conceito de economia laranja para enquadrar linguisticamente o conjunto das terminologias que se relacionam com as atividades de produção de bens e serviços culturais e criativos, como é o caso das indústrias culturais, indústrias criativas ${ }^{2}$, indústrias do ócio, indústrias do entretenimento, indústrias de conteúdos, indústrias protegidas pelos direitos autorais, economia cultural e economia criativa.

Ao conjunto de atividades que de modo encadeado permite que as ideias se transformem em bens e serviços culturais, cujo valor é determinado por seu conteúdo de propriedade intelectual, denomina-se economia laranja (RESTREPO E MÁROUEZ, p.40).

0 termo economia criativa foi popularizado em 2001 pelo escritor britânico e gerente de mídia John Howkins. Apesar de reconhecer as atividades e processos culturais como sendo o núcleo de uma nova e poderosa economia, a UNESCO $(2013$, p.19) está preocupada com as manifestações de criatividade em domínios que não seriam entendidas como cultural (UNESCO, 2013, p.19). Antes de explorar as implicações mais ampla de criatividade, no entanto, é importante examinar os demais termos relacionados à economia criativa.

Neste artigo, embora a terminologia empregada seja predominantemente economia criativa, em virtude do seu reconhecimento e aceitação no mundo ocidental, algumas proposições farão alusão explícita à economia laranja, por esta conjugar melhor a intersecção entre a economia subterrânea, a economia social, a economia cultural e a própria economia criativa.

Não se pretende chegar a um consenso final sobre os conceitos que orbitam a economia criativa. 0 que se busca é entender as nuances da economia criativa, a fim de apoiar o seu avanço como uma opção viável para o desenvolvimento em nível local e regional. Procura-se também fornecer uma análise do contexto e os contornos da economia criativa no que se refere ao desenvolvimento econômico e social em nível local (UNESCO, 2013).

A construção de níveis adequados de maturidade nos espaços de cultura e na gestão dos processos de negócio das áreas finalísticas não é um desafio trivial ou um projeto de curso rápido. Independentemente da competência dos gestores ou da proposição de novas regras para fluxos e processos, seu sucesso, requer a construção de alternativas que demonstrem capacidade de reduzir prazos e cuidar, paralelamente, de:

- aprimorar os espaços de cultura, reduzindo erros, perdas, atritos e disfunções,

- gerenciar o crescimento e as mudanças visando a construção de um espaço colaborativo e inovador para o futuro,

1 Autores com experiência nas atividades de exploração e aconselhamento de assuntos culturais, de solidariedade e criatividade vinculadas ao Banco Interamericano de Desenvolvimento (BID).

2 Encontra-se disponivel no relatório especial da UNESCO (UNESCO, 2013), uma seção que trata das definições e terminologia relacionadas às indústrias cultural e criativa e economia cultural. 
- construir uma cultura e uma prática de estabilidade, responsabilidade e de maturação continuada sobre os processos de trabalho e fluxos de informação, e

- adicionar maior transparência e rastreabilidade aos processos e decisões dos entes organizados.

Com o intuito de potencializar a evolução dinâmica das interações criativas e redes evolutivas de colaboração entre agentes individuais e coletivos, o escopo das atividades criativas será repercutido em nível de ecossistema. Aqui, o sistema consiste de recursos criativos interligados, como recursos humanos, gestores públicos, artistas, profissionais e empreendedores, articuladores e canais de compartilhamento de conhecimento, além de locais de criatividade, espaços de trabalho e plataformas físicas ou digitais (TARANI, 2011).

Partindo dessa visão dos ecossistemas criativos emergentes, este artigo define o espaço geográfico que concentra as atividades de ativação, promoção, articulação, formação e aconselhamento de negócios e empreendimentos culturais e criativos, que atuam individual, coletivamente ou em comunidade, como espaço organizativo laranja. Analogamente, Restrepo e Márquez (2013, p.156) atribuem a um edifício, um bairro ou qualquer espaço geográfico relativamente pequeno que contém uma concentração de negócios baseados na economia laranja, o conceito de cluster criativo.

No relatório da UNESCO (ibid., 2013, p.29), os clusters são descritos como uma concentração local de espaços, empresas e empreendimentos de produção de um determinado produto ou serviço criativo. Tomados em conjunto, esses clusters geram os processos de aglomeração em grande escala que estão entre as condições necessárias para o surgimento de territórios criativos. Esses processos, por sua vez geram muitas externalidades positivas.

0 objetivo neste estudo é debater aspectos de tecnicalidade frente às transformações provocadas pelas inovações tecnológicas, sociais e regulatórias em andamento, e as mudanças que essas novas realidades exigem do negócio criativo em rede. Por sorte, as reflexões e questionamentos sobre elementos constituintes dos modelos e abordagens existentes podem conduzir o processo de gestão e governança de instituições que atuam em espaços de cultura, compreender as restrições, os critérios, as condicionantes e os elementos determinantes para formulação dos planos estruturantes do sistema de governança, compreender as metodologias e ferramentas que facilitam o preparo e o emprego da tecnologia nos negócios criativos e compreender metodologias e ferramentas para desenvolver processos de gestão com base no diagnóstico e avaliação de métodos sistêmicos.

Criar, inovar e mudar depende essencialmente da atuação humana, seja de forma isolada ou não. 0 fato é que a cultura humana, com toda a sua complexidade, ambiguidade e múltiplas potencialidades, está no centro do processo de mudança (GHARAJEDAGHI, 2006, p.85).

Os próximos capítulos estão organizados segundo a proposta original do artigo, a começar pela discussão dos aspectos condicionantes para se pensar o desenvolvimento 
da economia criativa, passando pela discussão sobre tipologias e análise de redes sociais, para depois descrever a estratégia empreendida para a investigação, para ao final repercutir o desafio da estruturação do problema, com base numa investigação de campo, e a identificação de elementos centrais da arquitetura de um sistema de gestão dos espaços organizativos laranja a partir de uma experienciação.

\section{Condicionantes para o desenvolvimento da economia criativa}

Partindo do pressuposto de que um dos recursos chaves para um novo modelo de desenvolvimento econômico, social e cultural é a criatividade humana (CORAZZA, 2013), o desafio posto é alavancar um conjunto de atividades de uma coletividade humana, relativas à produção e ao consumo das riquezas, de modo a aguçar o espírito inventivo, a criatividade artística e a capacidade de criar coisas novas.

Em tempos de uma economia fortemente baseada no conhecimento, abre-se um enorme campo de possibilidades criativas, para a invenção, a ciência, as artes, tornando também a cultura um elemento central das estratégias transformadoras dos negócios e do desenvolvimento em todas as suas dimensões (ZARD0, 2005).

Desenvolver o potencial da economia criativa envolve a promoção da criatividade global das sociedades, afirmando a identidade singular dos lugares onde ela floresce e se ramifica, melhorando a qualidade de vida dos indivíduos instalados, reforçando a imagem e prestígio local e fortalecendo os recursos para imaginar a diversidade de novos cenários futuros (UNESCO, 2013, p.12).

Para Howkins (2013), a economia criativa pode ser definida como processos que envolvem criação, produção e distribuição de produtos e serviços, usando o conhecimento, a criatividade e o capital intelectual como principais recursos produtivos.

Avançando na visão pragmática do desenvolvimento da economia criativa, o conceito de indústrias criativas tem sua origem em 1997, com a decisão do governo Inglês de instituir a Creative Industries Task Force (CITF) como atividade central de seu novo Departamento da Cultura, Mídia e Esportes (CORAZZA, 2013), concentrando-se inicialmente nas atividades de setores criativos, como: publicidade, arquitetura, artes e antiguidades, artesanato, design, design de moda, filme, software para lazer interativo, música, televisão e rádio, artes performáticas, mercado editorial e software.

0 modelo inglês de desenvolvimento da indústria criativa, apesar de ser paradigmático, mostrou-se insuficiente e inadequado para ser adotado em outros países do Reino Unido, além de nações européias e mais tarde de países latino-americanos, cujas preocupações centrais dizem respeito à transfiguração dos espaços de cultura locais e suas singularidades em termos vocacionais e desconstruindo suas próprias produções e consumos culturais em favor da inserção de novos usos e costumes (CORAZZA, 2013; HESMONDHALGH E PRAT, 2005). 
A singularidade é vista como uma condição desejada para poder afirmar a diferença, de tomá-la como ponto de partida para estabelecer relações de criatividade, invenção, e afirmação do diverso (ALBUQUERQUE JÚNIOR, 2007, p.22).

0 processo de desenvolvimento da economia criativa não é monolítico nem tampouco reducionista. Exige uma visão holística do desenvolvimento humano, ou seja, um tipo de desenvolvimento que amplia as escolhas das pessoas, faz com que seja possível e necessário para transformar os aspectos de engajamento e análise. Nessa perspectiva mais ampla, a criatividade e a cultura são reconhecidas pelas múltiplas contribuições que oferecem ao desenvolvimento, incluindo a geração de energia social, confiança e engajamento, permitindo que os indivíduos e grupos aspirem e imaginem futuros alternativos (UNESCO, 2013, p.17).

A transculturação de experiências e modelos é uma marca do desenvolvimento cultural. Darcy Ribeiro assevera que, de acordo com a análise de Peter Burke, o Brasil é um país essencialmente resultante do hibridismo cultural, onde a economia da cultura e desenvolvimento local implicam articular modelos ou laboratórios de referência locais que assumem essa lógica. Consequentemente, o modelo de hibridização de espaço de cultura e da racionalidade instrumental de negócio do discurso modernizador capitalista, a lógica ou modelo anglo-saxão de indústrias criativas na função da memória e das identidades das culturas populares no Brasil, deve-se considerar que este é o eixo diferencial estratégico do Plano Nacional de Cultura (SIERRA, 2013a).

Ao refletir sobre cultura e desenvolvimento, Burity (2007, p.54-55) sugere primeiro identificar o lugar do desenvolvimento na cultura e depois identificar o lugar da cultura no desenvolvimento. Para além da lógica estritamente econômica o que se busca é uma reflexão sobre os impactos do desenvolvimento na cultura e o verdadeiro ganho para a sociedade.

0 cenário contemporâneo passa a ter um processo de recuperação do lugar da cultura no desenvolvimento, diferentemente de outrora, cujos modelos de desenvolvimento até a década de 1940 não trazia no seu bojo a ideia de lugar, de história ou de condicionamento (BURITY, 2007, p.60).

A dinâmica da globalização veio acompanhada de movimentos de ressignificação do local, de suas culturas, de sua valorização e até descoberta, na medida em que sentimos necessidade de ter raízes, de ter identidade, de nos singularizar em certos aspectos face aos avassaladores processos de simplificação de modos de ser, da erosão genética e cultural, da mesmice que veio atrelada à circulação de certos símbolos com pretensões dominantes e universais (ZARD0, 2005).

0 desenvolvimento da economia criativa geralmente é caracterizada pela participação dos entes governamentais. Diversos relatos sobre políticas públicas voltadas às indústrias criativas (CORAZZA, 2013; FLEW, 2012; GIRARD, 1982; VOLKERLING, 2001), mesmo que estas não fossem reconhecidas como tal, remontam as décadas de 1980 e 1990, período no qual se registra várias iniciativas governamentais de países como 
Inglaterra, Austrália, Canadá e Nova Zelândia, além de instituições como a UNESCO e suas subsidiárias, que se empenharam para levar adiante os empreendimentos e o setor de criatividade cultural.

É cada vez mais notável a inclusão da problemática cultural na agenda de desenvolvimento devido aos novos contextos criados pelas transformações do capitalismo cultural e capitalismo cognitivo. Estes movimentos chamam a atenção sobre o instrumentalismo das políticas culturais, os quais enxergam na cultura um recurso para alcançar outros fins, primordialmente econômicos, mas também políticos e sociais (BAYARD0, 2007, p.68).

As políticas culturais devem ser pensadas de modo a assimilar a singularidade, permitindo a elaboração e expressão do diverso e não da identidade. Esta visa sustentar as macro-políticas culturais que não conseguem alcançar a condição de singularidade existente no microcosmo dos agentes de cultura (ALBUQUERQUE JÚNIOR, 2007, p.22).

A economia criativa não é um único caminho de desenvolvimento, mas uma infinidade de diferentes trajetórias locais, encontradas em cidades e regiões de países em desenvolvimento (UNESCO, 2013, p.15).

Para fortalecer e multiplicar os esforços, além de permitir capturar variáveis importantes do ecossistema local da economia criativa, Restrepo e Márquez (2013, p.165) reforçam a necessidade de se incrementar espaços de cooperação e colaboração para transferir experiências, acordar conceitos fundamentais, identificar variáveis comuns e fortalecer trabalhos de agregação e comparação.

Para além dos espaços de cultura e dos territórios criativos, existem outras questões essenciais a compreender no tocante ao desenvolvimento da cadeia de valor da economia criativa. A começar pela natureza disforme dos produtos e serviços criativos, uma parcela dos quais apresenta um alto valor agregado, mas que não é percebido pelo comércio tradicional, como é o caso das artes, artesanatos e artes cênicas, dificultando sua afirmação pela inadequação de patrocínios e contratos comerciais.

Outro aspecto a considerar é a própria atuação do indivíduo. Ao exercitar sua imaginação e seu poder de criação, o indivíduo poderá desenvolver atividades exuberantes que resultem na produção de produtos ou serviços criativos, sem com isso ter a exata noção de como deverá ser explorado seu valor econômico (HOWKINS, 2013).

Pensar o desenvolvimento da economia criativa envolve também a capacidade de gerenciar espaços de criatividade que se constituem num continuum: partindo dos espaços mentais, fortemente acoplados, até espaços organizativos laranja que podem estar esparsamente distribuídos numa localidade, região ou país com dimensões continentais como é o caso do Brasil, apresentando-se fracamente acoplada.

Avançar na reflexão sobre o perfil das práticas culturais da população exige que se parta da dinâmica de pluralidade, no tocante ao plano da produção, e de unificação, no plano do controle de distribuição e consumo, condição para que se estabeleça uma política pública articulada que contemple as várias dimensões da vida cultural (BOTELHO, 173). 
Em face da economia criativa ser difícil de gerir e de alto risco, as grandes organizações que podem diluir o risco por meio de um portfólio de produtos e serviços terão mais facilidade para desenvolvê-la. Com acúmulo de bens, grandes economias de escala comandam a produção e o controle de sistemas de distribuição, e são uma barreira significativa à entrada de pequenos empreendedores. No entanto, nos cenários dos países em desenvolvimento, os laços históricos, relacionamentos e dependências de trajetória são fatores crucialmente importantes de sucesso (UNESC0, 2013).

0 acesso é chave para o desenvolvimento da economia criativa. Um dos requisitos fundamentais é a infraestrutura disponível. A versatilidade natural das atividades que compõem a economia criativa permite potencializar a capacidade de criar valor adicional a qualquer infraestrutura que forneça conectividade para o intercâmbio físico ou virtual. Em ambos os casos, os espaços se reinventam, enriquecem e apropriam com as intervenções artísticas e criativas (RESTREPO E MÁRQUEZ, 2013, p.177).

Em sintese, estes são os fatores condicionantes para o desenvolvimento do ecossistema local de economia criativa no Brasil, prospectados na literatura acadêmica e especializada sobre economia criativa:

- criatividade a partir da coletividade humana,

- visão holística do ecossistema local de economia criativa,

- visão holística do desenvolvimento sociotécnico,

- contribuição e impacto social,

- políticas públicas de promoção cultural e criativa,

- preservação da singularidade e diversidade local,

- desenvolvimento de espaços de cooperação e colaboração, e

- definição de cenários tópicos dos países em desenvolvimento (tropicalidade do caso brasileiro).

Essa capacidade de aglutinação de forças e o poder de engajamento esperados para o desenvolvimento dos ecossistemas criativos passa seguramente pela formação de redes sociais de alcance regional, nacional e supranacional. Entretanto, há que se observar a governança colaborativa (CAIUBY, 2011), de modo a viabilizar o poder e potencial da cocriação através das redes sociais. 


\section{Modelo de Desenvolvimento em Redes}

A vida acontece em rede (BARABÁSI, 2009). As redes se constroem a partir das conexões de elementos ou seres interagentes. Se na rede social as relações iniciam-se a partir do desejo de conexão dos sujeitos, a sua manutenção exige a superação de posições contraditórias e a assimilação dos conflitos existenciais, auto-organização e orientação a propósitos.

As mídias sociais alcançaram um patamar tecnológico de conectividade em nível mundial, potencializando a inserção contínua de redes sociais que oferecem meios para a articulação coletiva e autocomunicação das massas. Ao assumir o modelo de redes, Hakansson e Snehota $(1989$, p.197) indagam sobre o modo como o comportamento interativo poderá ser direcionado e gerido no ciberespaço.

A dinâmica social oriunda do ciberespaço incita a capacidade de comunicação e circulação de informações, com isso disseminando a liberdade, e, como consequência, conforme referido, aprimorando a inteligência coletiva (LEMOS E LÉVY, 2010, p. 43), pois o "ciberespaço permite uma liberdade de expressão e de comunicação em escala planetária absolutamente sem precedente" (ibid., p. 52).

0 modelo de rede sugere uma outra abordagem para a questão da efetividade da gestão nas organizações. Nesse sentido, a relação com o contexto é a questão central da estratégia. Relacionar com o contexto, ou seja, criar uma identidade distinta, é algo que tem de ser gerido. Dada a relatividade do conceito de contexto, este é concebido não como determinado antecipadamente, ou pré-determinado, mas da forma como é deliberado, que não pode ser avaliado (HAKANSONN E SNEHOTA, 1989).

A identidade estratégica, a base da efetividade, é alcançada pelo comportamento de interação de indivíduos em interação. Interação é o fluxo de eventos que, em última instância determina a efetividade e constitui estratégia. Assim, a efetividade de uma organização - sua estratégia - é baseada no comportamento interativo (ibid.).

Ao assumir que a definição de rede pode significar conjunto de seres, estabelecimentos ou organizações que trabalham comunicando entre si, alguns desdobramentos podem ser observados. Primeiramente, os nós ou atores, vínculos e fluxos que constituem os elementos básicos da rede (GARROSSINI, CABALLERO e MARANHÃO, 2011), podem formar diversos tipos de arranjos que determinarão a tipologia da rede.

As redes sociais sistêmicas, na concepção adotada por Aun, Esteves de Vasconcellos e Coelho (2012), correspondem a um fenômeno que deve ir ao encontro das relações humanas, deslocando a lógica dominante para as conexões entre indivíduos que necessita interagir, criando vínculos e colaboração.

0 foco passa a estar nas relações, não só as relações entre elementos do sistema e deste com seu meio, mas também as relações entre o sistema e aquele que o descreve e trabalha com ele. Amplia-se o foco: do elemento (o indivíduo) para o sistema (um espaço organizativo, um grupo de trabalho, uma instituição), e para os sistemas de sistemas (os ecossistemas, as redes sociais, as comunidades, as nações, as comunidades internacionais) (AUN, ESTEVES DE VASCONCELLOS E COELHO, p.94). 
Uma possibilidade de tipologia de rede social prevê a inclusão de hubs criativos, os quais segundo Restrepo e Márquez (2013, p.156), correspondem a centros de conexões, onde os próprios clusters, infraestruturas especializadas, capitais, talentos e tecnologias se concentram, independentemente de sua proximidade geográfica.

Ao analisar as implicações do modelo de rede, tem-se a impressão de que, se o ponto de vista de rede é adotado, vai se constituir num desafio para a visão predominante da organização como uma função de produção. 0 modelo de rede leva a uma visão bastante diferente do alcance e papel da organização monolítica (GARROSSINI, 2010). A ênfase na articulação de atividades e recursos dentro de uma rede, como uma tarefa primordial da organização, sugere que o negócio deve ser concebido como uma função de transação, em vez de uma função de produção. Tal conceito de negócio pode levar naturalmente a uma mudança de foco, distanciando do controle dos recursos para alcançar a integração de recursos, e distanciando da gestão da ação em relação à gestão de reação (HAKANSSON E SNEHOTA, 1989, p.198).

0 conhecimento é um fenômeno inerentemente social que se desenvolve a partir de interações comunicativas complexas realizadas em estruturas sociais. Uma das abordagens da estrutura de comunicação mais conhecidas é análise de redes. Elas representam um meio sistemático de examinar a configuração geral das relações, tanto formais quanto informais, em uma organização (JOHNSON, 2011, p.23-24).

Em virtude de sua abrangência, a análise de redes é usada por quase todas as ciências sociais para estudar problemas sociais específicos (JOHNSON, 2011). Ao aplicar a análise de redes num determinado espaço social, possibilita a identificação dos problemas em comum, a discussão de diversas temáticas ao mesmo tempo e pensar políticas públicas de forma holística, dialogando sobre o problema como um todo.

Um dos instrumentos chave para a promoção e indução da economia criativa no Brasil são as políticas públicas. Apesar de estar interessada no desenvolvimento de políticas de saúde, a pesquisa de Garrossini (2010) traz uma importante contribuição ao abordar os aspectos centrais na identificação das ligações entre os autores envolvidos, o processo de estruturação das redes de conhecimento e informação e os recursos utilizados com o intuito de promover a ampliação do espaço de participação para a formulação de políticas públicas.

As redes conectam os atores de uma rede, os sistemas de um ecossistema e os ecossistemas entre si. Tudo pode se conectar, criar vínculos, além de trabalhar em rede. A sociedade em linha passa a se constituir numa sociedade em rede, de inclusão social, conectando e definindo objetivos que engajam todos na rede e permitindo a formação de espaços colaborativos.

Antes mesmo da definição de um modelo de rede para interconectar os atores da economia criativa, o pensamento de rede recobre as reflexões sobre a configuração dos espaços organizativos laranja, incluindo suas excentricidades e externalidades. Barabási, (2009, p.194) defende que o pensamento de rede está em via de invadir todos os domínios da atividade humana e a maioria dos campos de investigação humana. Deve-se observar, 
todavia, que as redes reais são caracterizadas pela aleatoriedade e acaso que efetivamente desempenham importante papel em sua construção (ibid., p.193).

As conexões quantificam as várias interações que ocorrem entre os elementos de um espaço organizativo laranja, envolvendo a articulação dos segmentos culturais locais, os convênios, subvenções e parcerias com entidades de fomento e projetos de promoção de eventos. Há, portanto, que desenvolver a capacidade de fortalecer o desejo de conexões para a formação de redes sociais auto-organizadas.

Ao pensar a modelagem da rede, Barabási $(2009$, p.192) destaca a necessidade de celebrar princípios organizacionais que governam as complexas redes que nos cercam. 0 nível de complexidade está expresso na relação das diversas ações que se compõem em torno da rede, no modo de gestão pública, nos mecanismos necessários para se montar uma rede que seja orientada à promoção de conexões, na formação de redes e redes de redes.

A sociedade da colaboração, que emerge da rede, segue um modelo de relações horizontal e circular, superando as relações de poder piramidal, para tornar capaz a produção de valor, significando e re-significando aprendizado e comunicação. 0 fenômeno da "primavera árabe" sintetiza o modelo múltiplo de ser ao invés de modelo único de ser, facilitando a marcação de território. Nessa ótica, Barabási (2009) lembra que o pensamento hierárquico não se coaduna com uma economia em rede, já que esta valoriza a rede enquanto locus de conexão.

\section{Estratégia de pesquisa}

A ciência desenvolveu-se nos últimos quatro séculos acreditando que, para compreender o mundo e descobrir as leis de seu funcionamento, deveria analisar em partes os todos complexos, inclusive tirando os objetos de seus contextos e levando-os para estudá-los nos laboratórios, por meio de experimentos que mostrassem claramente a causa de cada fenômeno observado. Instalaram-se a fragmentação do objeto de estudo, a compartimentação dos campos do saber, as especializações. Desenvolveu-se uma forma de pensar disjuntiva que, diante de uma nova explicação para algo, tende a rejeitar a anterior (AUN, ESTEVES DE VASCONCELLOS E COELHO, 2012, p.93).

Diante do exposto e ciente da complexidade sistêmica inerente ao ecossistema local da economia criativa, onde estão inseridos os espaços organizativos laranja, a concepção de pesquisa adotada é de natureza exploratória e descritiva, baseada em investigação de campo, bibliográfica e documental. 0 envolvimento dos pesquisadores na unidade de análise vai além do problema sob investigação, cuja observação participante é o meio utilizado para viabilizar o contato intersubjetivo e dialógico com os agentes envolvidos na implantação de um espaço organizativo laranja.

A ação humana, sob o enfoque sistêmico, repercute sobre as demais partes interdependentes do ecossistema local da economia criativa, que por sua vez (as partes) refletirão nas ulteriores 
decisões humanas. Portanto, não é trivial para o pesquisador capturar e interpretar a dinâmica de relações e comportamentos sociais, de modo a apreender o conhecimento interpretado, o qual segundo Antunes de Sá (2011), é uma representação possivel do real dentre várias outras possíveis.

Os níveis macrofísico, microfísico e virtual estendem a visão tópica da realidade (MORAES E VALENTE, 2008, p.21). As visões imbricadas do ecossistema local da economia criativa modulam os pontos de vista dos agentes públicos e privados quanto à constituição dos espaços organizativos em rede. Um dos propósitos deste estudo é prospectar os elementos constituintes das realidades observadas nesse ecossistema.

Por exemplo, do ponto de vista ontológico, o ser e sua realidade se constituem em uma dinâmica não linear, de natureza recursiva, retroativa, indeterminada, cujo padrão de funcionamento acontece em rede (MORAES e VALENTE, 2008; CAPRA, 1997; MATURANA, 1999).

A participação do sujeito de pesquisa não se restringe a apenas observar passivamente a conjuntura socioeconômica, cultural e política que caracteriza o ecossistema local da economia criativa ao qual está inserido. Há uma interação conjunta, partindo de uma lógica circular, conforme resenhado por Antunes de Sá (2011):

O sujeito de pesquisa participa com toda a sua inteireza, sua corporeidade e suas estruturas cognitivo-emocionais, o que indica que o conhecimento produzido, elaborado, sistêmico e interpretado é uma emergência biopsicossociogênica. Pensar de forma complexa é pensar no processo, é tecer junto elementos constituintes de uma dada realidade social, física ou natural (ibid., p.249).

0 princípio da incerteza, do físico Heisenberg, o funcionamento das partículas subatômicas, os saltos qualitativos dos sistemas dissipativos químico nos pontos de bifurcação, o funcionamento fisiológico dos seres vivos, apontaram: a complexidade organizada do universo; a instabilidade dos sistemas e a autonomia de muitos deles; a construção intersubjetiva da realidade por aqueles que a percebem, construção essa que se dá num espaço consensual, constituído na linguagem (AUN, ESTEVES DE VASCONCELLOS E COELHO, 2012; ESTEVES DE VASCONCELLOS, 2013).

0 contato intersubjetivo e dialógico com os sujeitos de pesquisa é marcado pela descrição do modo como eles se comportam realmente e não como deveriam se comportar. Com efeito, o método dialético é parte da premissa de que, na natureza, tudo se relaciona, se transforma e há sempre uma contradição inerente a cada fenômeno. Nesse tipo de método, para conhecer determinado fenômeno ou objeto, o pesquisador precisa estudá-lo em todos os seus aspectos, relações e conexões, sem tratar o conhecimento como algo rígido, já que tudo no mundo está sempre em constante mudança.

Gharajedaghi (2006, p.84) ressalta que a interação dialética entre as realidades objetivas e subjetivas está no cerne de um processo responsável pelo desenvolvimento dinâmico das sociedades humanas. A teoria dialética das relações integra os elementos 
da teoria psicodinâmica das relações objetais, a visão dialética no sentido hegeliano e a Teoria Geral dos Sistemas. De modo a quebrar as narrativas cristalizadas, o argentino Saul Fuks dedicou-se ao trabalho com as comunidades, criando contextos dialógicos (AUN, ESTEVES DE VASCONCELLOS E COELHO, 2012, p.35).

As comunidades científicas adeptas ao princípio de cientificidade de Newton e Descartes, vem reconhecendo que não poderiam mais continuar pensando um mundo estável, cujos princípios de funcionamento, expressos em leis deterministas e reversíveis, iriam permitir-Ihes prever e controlar todos os fenômenos do universo (ibid., p.98). Enquanto mantiver a fragmentação disciplinar, a complexidade sistêmica será primeiramente tratada pelos vieses especialistas, não sendo suficiente para apropriar-se da epistemologia do pensamento sistêmico.

As políticas sociais são geralmente idealizadas apenas pelos que estão no ápice de uma pirâmide e aplicados por agentes aos usuários ou beneficiários do sistema. A visão sistêmica implicará a convicção da impossibilidade de implantação de programas com essas características, além de evidenciar que não é o especialista que detém as melhores soluções. A preocupação será a de criar contextos de coparticipação, em que todos os implicados - governo, agentes e usuários - possam coconstruir soluções viáveis e satisfatórias, assumindo todos suas responsabilidades, com a consequente manifestação da autonomia. Em vez dos especialistas em conteúdos ou em estratégias para soluções de problemas, atuarão os peritos na criação de contextos de autonomia para o sistema (AUN, ESTEVES DE VASCONCELLOS E COELHO, 2012).

0 surgimento da Cibernética e da Teoria Geral dos Sistemas em meados do século XX trouxeram uma contribuição paradigmática para as Ciências, além de possibilitar a concepção das organizações como um sistema. A ciência tradicional se fundamenta em três pressupostos básicos - simplicidade, estabilidade e objetividade. Já a ciência contemporânea emergente pretendeu basear-se nos princípios da complexidade, instabilidade e da intersubjetividade, os quais de modo indissociável favorece a investigação sobre os sistemas determinado pelo problema (AUN, ESTEVES DE VASCONCELLOS E COELHO, 2012; ESTEVES DE VASCONCELLOS, 2013).

Os critérios de cientificidade compartilhados pelas comunidades científicas correspondem aos princípios diretores da investigação científica, refletindo seu paradigma, sua epistemologia, sua visão de mundo, as crenças e os valores com que estão comprometidos (ESTEVES DE VASCONCELLOS, 2013).

0 quadro de referência desta pesquisa está centrado na ultrapassagem dos pressupostos da simplicidade, da estabilidade e da objetividade, dando lugar aos novos pressupostos da complexidade, da instabilidade e da intersubjetividade, conforme consta nos trabalhos de (AUN, ESTEVES DE VASCONCELLOS E COELHO, 2012; ESTEVES DE VASCONCELLOS, 2013).

A opção etnográfica se deve à necessidade de trazer respostas a problemas específicos sobre como ir a campo de forma a produzir resultados válidos. Por meio da descrição 
densa proporcionada pela etnografia é possível alcançar a produção de sentidos nos grupos sociais, que as redes sociais têm como um dos objetos principais.

\section{Estruturação do problema}

Em meados do século XX a pesquisa operacional surge como uma ferramenta poderosa de aprendizado para permitir às organizações atuarem de forma mais eficiente, segundo a definição de modelos apropriados para a resolução de problemas de ordem prática. De igual modo, emerge nesse período o embrião do pensamento sistêmico e da cibernética que se propõem a tematizar sobre as peculiaridades e implicações sistêmicas nas organizações sociotécnicas e a estruturação de mecanismos de comunicação e controle, respectivamente.

Com o passar do tempo essas três áreas de conhecimento - pesquisa operacional, pensamento sistêmico e cibernética, evoluiram significativamente de forma isolada e conjuntamente em virtude de suas implicações e aplicações em contextos organizacionais. 0 resultado desta convergência pode ser verificado nos campos da pesquisa operacional flexivel (SOR - do inglês Soft Operational Research) e métodos de estruturação de problema (do inglês Problem Structuring Methods).

Métodos de pesquisa operacionais flexíveis são cruciais quando se deve considerar muitos pontos de vista das partes interessadas e quando o problema que está sendo enfrentado é de natureza complexa (SEAGRIFF E LORD, 2009).

Pensar a estruturação de um problema complexo pressupõe o desenvolvimento das atividades de diagnóstico e avaliação multidimensional que considere elementos entremeados à teoria e prática, ao geral e particular, ao global e local. Fundamentalmente, o desafio é ampliar a visão das realidades circunscritas no ecossistema local da economia criativa com vistas a alcançar novas possibilidades de ação e novas correlações de força que possam ocorrer.

0 modelo de organização dos espaços culturais proposto pela Secretaria de Economia Criativa do Ministério da Cultura é variável em função do território, sob a denominação de Incubadoras Criativas, apresentando uma hibridização em termos da estrutura transversal que incorpora elementos internos de sua operação, conjunturas socioculturais e econômicas, pontos de cultura existentes, Secretarias de Cultura Estaduais e outras instituições públicas e privadas. Para torná-los factíveis, a transversalidade genuína que acompanha o processo de inovação sociocultural originário deve ser compreendido para se definir cursos de ação efetivos e sustentáveis.

0 caráter transversal da cultura faz com que se preste menos atenção a suas possibilidades alavancadoras de dinâmicas cognitivas, inovativas, criativas (ZARDO, 2005). Existe, portanto, um enorme desafio em termos de gestão das Incubadoras Criativas e demais espaços organizativos laranja e dos negócios vinculados à cultura, ao mesmo tempo 
que existe um enorme potencial dos negócios que podem surgir das chamadas indústrias criativas, que colocam a cultura e a criatividade em seu processo de produção e trabalho.

0 estudo etnográfico propiciou a descoberta de problemas socioculturais envolvendo os agentes criativos, fruto da análise da configuração atual do ecossistema local observado, em termos de fatores socioculturais, econômicos, políticos e tecnológicos. Com efeito, os espaços organizativos laranja desempenhariam o papel de articuladores da economia criativa, atuando como catalisadores do processo de inovação e criatividade dos agentes criativos e sintetizadores dos movimentos e tendências observadas no ecossistema de economia criativa.

Com o intuito de dialogar com os agentes criativos, públicos e privados, circunscritos no ecossistema local da economia criativa, o estudo do problema envolveu as seguintes indagações:

- Qual a relação entre a estratégia institucional e os outros instrumentos de planejamento setorial da economia criativa em rede?

- Quais são os instrumentos de avaliação e controle dos processos para direcionamento e desenvolvimento do negócio criativo?

- Quais são os blocos de construção que contribuem para o gerenciamento do conhecimento do negócio e das tecnologias?

- Quais são as dimensões estruturantes da governança do ecossistema local da economia criativa?

- Qual o impacto sociocultural da atuação de espaços organizativos em rede?

Partindo das indagações formuladas, definiu-se o eixo central do trabalho a partir da declaração da seguinte questão de pesquisa: que fatores facilitam o processo de tomada de decisão dos gestores de um espaço organizativo laranja de modo a contemplar os princípios e as diretrizes emanadas pelo ecossistema local de economia criativa?

\section{ESTUDO ETNOGRÁFICO DE UM ESPAÇO ORGANIZATIVO — REDE DE INCUBADORAS BRASIL CRIATIVO}

A economia criativa brasileira apresenta suas peculiaridades em relação ao modelo de desenvolvimento anglo-saxão por apresentar as condicionantes dos territórios, a tropicalidade, a necessidade de inclusão social e a afirmação dos agentes criativos nas suas localidades, além da necessidade de suportar as premissas de sustentabilidade. O PSEC (2011, p.33) apresenta estes princípios norteadores para a economia criativa brasileira com base em: diversidade cultural, inovação, sustentabilidade e inclusão social. 
0 modelo de espaço organizativo proposto pela Secretaria de Economia Criativa do Ministério da Cultura (SEC-MinC), está pautado pela definição original de Criativa Birô, segundo a qual,

\begin{abstract}
"É um escritório público de atendimento e suporte a profissionais e empreendedores que atuam nos setores criativos brasileiros, por meio da oferta de informação, capacitação, consultorias e assessorias técnicas, entre outros serviços voltados para a qualificação da gestão de projetos, produtos e negócios de micro e pequenos empreendimentos criativos." (CRIATIVA, 2013, p.2)
\end{abstract}

As linhas de atuação propostas para esse espaço organizativo, que passou a ser denominado pela SEC-MinC como Incubadora [Estado] ${ }^{3}$ Criativo, do Programa de Incubadoras Brasil Criativo, estão assim organizadas (CRIATIVA, 2013, p.4):

- geração e difusão de informação,

- fomento a empreendimentos criativos,

- formação para profissionais criativos, e

- promoção de negócios criativos.

As Incubadoras Criativas estão sendo implantas em treze Estados brasileiros (CRIATIVA, 2013), fruto dos convênios de pactuação entre SEC-MinC e Secretarias Estaduais de promoção de cultura. 0 modelo de gestão proposto é baseado na conjugação das possibilidades de personalidade jurídica para o órgão gestor, estrutura organizacional e governança.

A estrutura organizacional da Incubadora é constituída de camadas. A camada interna contém o comitê gestor e a coordenação administrativa e financeira. Na camada seguinte encontram-se as coordenações de formação, empreendedorismo e inovação e articulação institucional e redes. Na última camada estão dispostos os agentes vinculados às essas três coordenações: instituições e formadores, consultores e assessores e articuladores regionais (CRIATIVA, 2013, p.18-19).

Quanto à estrutura de governança, estão previstas instâncias decisórias a começar pelo comitê gestor, passando pelo conselho administrativo até alcançar o conselho consultivo (ibid., p.20).

Para viabilizar a implantação das Incubadoras Criativas, a SEC-MinC firmou um acordo de cooperação com a Fundação Universidade de Brasília para desenvolvimento

3 Estado - inclui cada um dos treze Estados que compõem o Programa das Incubadoras Brasil Criativo. Como exemplo de Incubadoras, tem-se: Incubadora Pará Criativo, Incubadora Mato Grosso Criativo, Incubadora Rio Criativo, etc. 
de um projeto de suporte técnico e metodológico. Durante a fase de prospecção de um ecossistema local da economia criativa, onde se encontra uma dessas Incubadoras em implantação, a equipe de pesquisadores da Universidade de Brasília, entre os quais se encontram os pesquisadores deste artigo, desenvolveram um estudo etnográfico com base em observações diretas e indiretas, aplicação de entrevistas junto aos agentes de cultura, gestores públicos e equipe técnica contratada para gerir a Incubadora.

As atividades de observação e prospecção aconteceram nos meses de novembro e dezembro de 2013, incluindo levantamento de documentos, visitas aos espaços organizativos de cultura, seminários com empreendedores e agentes públicos ligados à cultura daquela localidade, além de entrevistas individuais e coletivas.

0 objetivo desse estudo foi evidenciar a diversidade de arranjos criativos, apresentando a estrutura atual do projeto, visando:

- formação de estruturas em rede e como organizar os processos dessa forma,

- ampliação das atividades para espaço permanente de reflexão e ação sobre economia criativa,

- constituição de rede de escritórios públicos de atendimentos e suporte, rede de pontos físicos de atendimento e estabelecimento de um ambiente de compartilhamento de modelos de negócios, processos e produtos,

- incentivo a formação entre pares incluindo parceiros institucionais, empreendedorismo, formação e compartilhamento de modelos criativos, além de articulação (indústria cultural e economia), e

- apresentação da estrutura do projeto pela Universidade de Brasília, considerando o que havia sido pactuado com a SEC-MinC.

As entrevistas tiveram como ponto central a apresentação e diálogo com os membros da equipe da Incubadora, agentes públicos e privados. As discussões oportunizaram a participação individual, onde cada um relatou suas experiências culturais e profissionais, e participação coletiva com relatos sobre a diversidade cultural daquela localidade, além de promover trocas de experiências entre os envolvidos.

A participação dos grupos de pesquisa indicou algumas características positivas no processo de implantação, incluindo as seguintes constatações: uma fração possuía experiência em desenvolvimento de projetos e orientação na resolução de problemas, outra demonstrou conhecimentos básicos sobre as áreas de atuação nas coordenações da Incubadora e como regra geral, todos têm consciência do grande desafio e do nível de complexidade que encontrarão no aparelhamento e constituição do espaço organizativo. 
De igual modo, foram realizadas entrevistas e encontros com agentes de cultura, empreendimentos e negócios criativos, além de gestores públicos e privados interessados.

\section{Elementos arquiteturais para sistema de gestão de espaços organizativos Iaranja}

Entre os fatores que impulsionam os padrões atuais de crescimento está o novo patamar de geração de rendas das nações, constituído pelos setores interligados que produzem bens e serviços simbólicos. A trajetória de desenvolvimento é hoje radicalmente diferente do modelo de desenvolvimento econômico de outrora, caracterizado pela baixa agregação de valor e pela organização clássica dos setores primário, secundário e terciário da economia, movendo-se para a concepção de cadeia de valor (UNESCO, 2013, p.36).

Nos últimos tempos as mudanças nos campos políticos, sociais, culturais e tecnológicos se acentuaram em função da grande volúpia desenvolvimentista do século XX. Zardo (2005) atribui a uma parcela dessas mudanças os reflexos da desmaterialização dos processos produtivos, passando a incorporar mais informação e conhecimento na produção de bens do que máterias-primas como aço, ferro, plásticos, carbono e energias fósseis.

Para lidar com a complexidade do ecossistema local da economia criativa, onde se encontra inserido o espaço organizativo laranja, o processo de apreensão gerencial da realidade ocorre sob a lógica dominante da multidimensionalidade, reconhecendo a interligação e a interdependência entre os fatos, fenômenos e eventos (ANTUNES DE SÁ, 2011; GHARAJEDAGHI, 2011; MORAES E VALENTE, 2008). A sumarização feita por Antunes de Sá (2011) resgata as circunstâncias definidoras da realidade sistêmica, segundo a qual a incerteza, instabilidade e dinamismo são indutores das modificações que acontecem em um de seus elementos constituintes, provocando ulteriores alterações nos demais elos das redes que a constitui (FRITJOF, 1997; MATURANA, 1999; MORAES E VALENTE, 2008).

A potencialidade e a vitalidade da cultura reside na sua capacidade criativa para enfrentar os desafios de emergir continuamente desejos e ideais. Este processo exige adaptação consciente e ativa, não uma aceitação passiva dos acontecimentos. É uma luta para a criação de novas dimensões, a valorização de novas realidades e, finalmente, o enriquecimento da imagem comum. É um processo de aprendizagem que envolve mudanças coordenadas em motivação, conhecimento e compreensão em todo o sistema social (GHARAJEDAGHI, p.85).

Um dos importantes desafios para os formuladores de políticas públicas é a obtenção de dados confiáveis sobre as atividades criativas e culturais. Dados agregados em nível nacional sobre os fluxos culturais, o tipo de informação necessária para compreender a dinâmica das cidades e regiões e que nem sempre estão disponíveis no momento de mapear as economias criativas locais (UNESCO, 2013, p.28). 
Todo o processo de preparação e aparelhamento do espaço organizativo laranja não se restringe a um tradicional planejamento estratégico. Há que se observar os elementos centrais do ecossistema local da economia criativa e do próprio espaço organizativo, uma vez que o sentimento das percepções e posicionamentos intersubjetivos, instabilidade do ambiente e complexidade sistêmica, subsidiará a formação conjunta e integrada dos cursos de ação consensuados.

A estrutura do espaço organizativo laranja contemplará as partes ou elementos centrais necessários para viabilizar a implementação dos processos e operações que sustentam a entrega da proposição de valor. Partindo da visão do modelo de negócio (CASADESUS-MASANELL E RICART, 2009; CHEN, 2009; OSTERWALDER 2011; OSTERWALDER 2004; ZARDO, 2005) e visão tradicional baseada no processo de administração estratégica (ROCHA et al., 2010; JOHNSON, SCHOLES E WHITTINGTON, 2007; MINTZBERG, 2000; SERRA, TORRES e TORRES, 2003; VALERIANO, 2009), consubstanciada pela visão baseada em recursos (ROCHA et al., 2010) e visão baseada na gestão superior dos stakeholders (ROCHA et al., 2010), pretende-se alcançar uma visão holistica (MATURANA, 1999), multistakeholder e ampliada das circunstâncias definidoras do ecossistema local da economia criativa para, em última análise, fornecer os subsídios estratégicos e táticos para a constituição e manutenção do espaço organizativo laranja, de forma sincrônica com sua capacidade de atuação.

A organização deve ser vista a partir da pluralidade de estrutura, função e processo, correspondendo ao cerne da teoria de sistemas de desenvolvimento. A pluralidade simplesmente afirma que sistemas podem ter estruturas múltiplas e funções múltiplas e serem governadas por vários processos (GHARAJEDAGHI, 2006).

0 uso de todas as três perspectivas de estrutura, função e processo como a fundação de uma metodologia holística pode ser justificada tanto por razões práticas e teóricas (GHARAJEDAGHI, ibid., p.110).

Tão importante quanto as perspectivas supracitadas, as cadeias de valor para criação, produção, distribuição e consumo que hoje estão sendo geradas localmente estão se manifestando de modo distinto, irregular e orientado ao contexto (UNESCO, 2013, p.33). Nesse sentido, cidades e regiões são um terreno privilegiado devido às densas redes de interação de pessoas, mercados e atividades.

Dadas as peculiaridades dos grandes centros urbanos, a emergência é a regra que prevalece (MATURANA, 1999), tornando seus contextos sociais, políticos e culturais altamente complexos e por vezes caóticos. No relatório da UNESCO (ibid., p.34) as cidades e regiões metropolitanas são tidas como agentes culturais por conta da emergente descentralização em curso dos poderes governamentais constituídos, fenômeno este que está ocorrendo em muitas partes do mundo, bem como pelo aumento da demanda dos cidadãos por amenidades de natureza cultural.

0 eixo de discussão passa a considerar os aspectos internos e externos, mas sobretudo atentando-se às fronteiras do sistema de interesse. Ao evidenciar o modelo de rede, 
Hakansson e Snehota (1989) inclui a interface organização-ambiente com base em três questões centrais da doutrina de gerenciamento estratégico: (1) as fronteiras organizacionais, (2) determinantes da efetividade organizacional, e (3) o processo de gestão de estratégia de negócios.

Um espaço organizativo laranja, enquanto organização sociotécnica, está imbricado numa teia de relações sociais, políticas e culturais, constituída sobre uma plataforma técnica e operacional. Gharajedaghi (2006, p.83) assevera que um sistema social não é constituído apenas pelos seus membros, como também pela relação de seus membros entre si e com o todo. 0 ponto de destaque, por consequência, não é a existência de uma relação, mas as hipóteses sobre a natureza da relação.

Partindo das premissas do pensamento sistêmico e da lógica circular da cibernética, incluindo a visão multidimensional de Gharajedaghi (2006), os elementos evidenciados e os achados da pesquisa empreendida, sugerem alguns elementos de diagnóstico e avaliação para a proposta de uma arquitetura de sistema de gestão do espaço organizativo laranja, a saber:

- domínio interno da organização com foco nas perspectivas de estrutura, funcionalidade e processos,

- domínio externo da organização com foco nas perspectivas dos contextos, stakeholders e modelos de negócio;

- cursos de ação estratégico e tático necessários para conduzir o negócio do espaço organizativo;

- horizontes temporais de curto, médio e longo prazos;

- tomada de decisão, incluindo compreensão, decisão e monitoramento; e

- identificação dos domínios de arquitetura social, técnica, da informação e do negócio.

Dentre tantos métodos e modelos com enfoque sistêmico que subsidiam a pesquisa operacional flexivel, o VSM ${ }^{4}$ e o $\mathrm{SSM}^{5}$ proporcionam um entendimento do ponto de vista sistêmico sobre as organizações de qualquer natureza. No primeiro caso para discutir a sua viabilidade sistêmica e no segundo para estruturar a situação-problema do sistema designado.

4 VSM - Viable System Model - Proposta original do inglês Anthony Staffor Beer, proeminente teórico da pesquisa operacional e gestão cibernética.

5 SSM - Soft Systems Methodology - Proposta original do inglês Peter Checkland, professor e cientista pesquisador da Lancaster University, com contribuições acerca de metodologias baseados no pensamento sistêmico e pesquisa-ação. 
Para compreender a complexidade da organização sociotécnica, o processo de investigação é baseado nas iterações de estrutura, função e processo em um determinado contexto, de modo a examinar pressupostos e propriedades de cada perspectiva distintamente para, em seguida, examinar a relação existente entre elas. Iterações subsequentes podem ser estabelecidas para validar os pressupostos, que permitirão encontrar compatibilidades ou conflitos identificados e dissolvidos. Ao dissolver os conflitos pode exigir re-conceituação das variáveis envolvidas. Finalmente, sucessivas iterações poderão produzir um projeto integrado (GHARAJEDAGHI, p.112).

Os espaços organizativos laranja não atuarão de forma monolítica. Em algum momento eles estarão conectados em redes sociais, o que facilitará a criação e o compartilhamento do conhecimento. Nenhuma organização é uma ilha (HAKANSSON E SNEHOTA, 1989). Ela deve ser observada sob as perspectivas dos domínios externo e interno.

Pensar a estratégia envolve a definição de processos necessários para a sua gestão. Hakansson e Snehota (1989, p.189) assume que a gestão da estratégia é vista como um processo de adaptação do padrão de atividades realizadas pela organização para as condições ambientais externas em que a organização atua. Gerenciar a estratégia, portanto, significa gerir o processo pelo qual o padrão de atividades a serem realizadas pela organização é concebido e depois criar as condições necessárias para que essas atividades sejam realizadas. Geralmente a gestão da estratégia é estressada porque o ambiente está sempre mudando, o que gera a necessidade de ser um processo contínuo.

Um dos elementos centrais para tecer os relacionamentos sociais dentro de cada rede vinculada ao espaço organizativo laranja e as inter-redes, é refletir sobre as possibilidades de atuação e operação, a saber:

- sensibilização e comunicação dos princípios de formação da economia criativa e pensamento de rede,

- modelagem da rede no formato auto-organizado, contemplando hierarquias de hubs para assegurar a coesão da estrutura,

- desenvolvimento de metas e mensuração para as redes,

- manutenção das redes sociais vinculadas com base em valores de atratividade e diversão,

- desenvolvimento de diretrizes e princípios centrais para governar a rede e a rede de redes para formatar as tomadas de decisão, em nível gerencial, com vistas à perenidade dos espaços e negócios criativos,

- estímulo ao aumento da capilaridade das redes e inter-redes, e 
- definição de processos e operações em nível de direcionamento, projeto, desenvolvimento e entrega (SLACK et al., 2006).

Sem contar com uma base sólida de informação e conhecimento, a tomada de decisão por parte dos gestores que atuam no ecossistema criativo, independentemente do aspecto funcional ou nível de capilaridade, torna-se uma tarefa árdua agravada pela baixa assimilação de metodologias de aprendizagem consistente com um mundo de complexidade dinâmica crescente, obrigando-os a fortalecerem os processos essenciais que suportam a organização. Por consequência, cria-se o desafio de expandir as fronteiras dos modelos mentais dos decisores e desenvolver instrumentos e mecanismos para compreender como a estrutura de sistemas complexos cria o seu comportamento em rede.

A decisão compreende três fases principais: descobrir as ocasiões em que deve ser tomada, identificar os possíveis cursos de ação e decidir-se entre um deles. Os executivos empregam grande parte do tempo estudando o ambiente econômico, técnico, político e social, procurando identificar condições novas que exijam novas ações. A maior parte do tempo é gasta com a identificação e a prospecção dos possiveis cursos de ação, restando uma pequena fração do tempo decidindo entre medidas alternativas, já tomadas para solucionar problemas já identificados e analisados em suas conseqüências (SIMON, 1972).

Em geral, o processo de tomada de decisão no ambiente organizacional se desenrola a partir das seguintes fases (SIMON, 1972), as quais terão implicação nos espaços organizativos laranja: (1) qual é o problema?, (2) Quais são as alternativas?, e (3) Qual é a melhor alternativa?

Como ponto de reflexão, o desenvolvimento de um bom planejamento, assessoramento técnico qualificado e ações-chave iniciais serão essenciais para ajudar a evoluir e manter um ambiente sociotécnico atendendo às necessidades da organização, com eficiência, eficácia e a um custo economicamente viável.

A ambivalência, a contradição constitutiva da economia intangível (imaterial) e os bens comuns, são produtivos à medida em que se pense o Programa de Incubadoras Brasil Criativo da SEC-MinC, os laboratórios locais ou incubadoras, como um espaço híbrido. Sierra (2013a) adverte que passamos de um processo de bifurcação e transição das novas formas ou sistemas de informações e de reprodução cultural, para um pensamento "de fronteira" e um projeto híbrido de laboratórios locais inspiradas na dinâmica dos atores e processos comuns que emergem no Brasil.

\section{Conclusões}

A pesquisa em curso teve como ponto de partida a observação da realidade plural dos espaços organizativos laranja que convivem com situações inusitadas por conta de uma série de desarranjos de cunho sociotécnicos, de decisões equivocadas ou precipitadas e 
de conseqüências danosas provocadas por incertezas e intempestividades do ambiente externo não controlado. Apesar de existir um grande repertório de abordagens prescritivas e descritivas para alavancar os negócios corporativos, ainda assim, há muitas questões mal resolvidas ou que sequer foram descobertas, impedindo que elas sejam apropriadas no cenário de um espaço organizativo sem um diagnóstico e avaliação consistentes.

Em meio a essas questões, as instituições são subsidiadas por instrumentos e mecanismos de governança e de gestão, implementados com base em modelos e metodologias diversas, sobre uma plataforma operacional, formando um mix singular que conduz a engrenagem corporativa. Posto isso, algumas indagações instigaram os pesquisadores a observar os fenômenos e fatos que condicionam e favorecem a introdução de modelos de gestão em espaços organizativos em rede.

A não compreensão do modo como as ações de um espaço organizativo laranja afeta outros espaços é uma limitação que facilmente poderá comprometer todos os segmentos da rede. 0 que se busca, em última análise, é combinar estratégias tradicionais com um melhor entendimento dos efeitos de rede.

Nos espaços organizativos laranja os gestores devem desempenhar um duplo papel de trabalhar para dentro e trabalhar para fora, lidando de forma sincrônica com as atividades de gestão e comunicação e as atividades de articulação e emancipação dos agentes e comunidades criativas.

Para superar o modelo de desenvolvimento da gestão pública, geralmente empregado de modo fragmentado, o ponto central é a reflexão sobre a natureza complexa do ecossistema local da economia criativa, onde as organizações são tipicamente sociotécnicas, como é o caso dos espaços organizativos laranja. A emergência, a instabilidade, o intersubjetivismo, as incertezas e a intempestividade são as palavras de ordem que orbitam as realidades desse ecossistema.

Nunca é tarde demais para reconhecer que o processo de desenvolvimento da economia criativa pressupõe o desenvolvimento intelectual e cognitivo dos agentes criativos, a assunção do estágio de produção e geração de valor, culminando com a economia criativa, que deve ser sempre avaliada em termos de retorno socioeconômico e cultural.

\section{Referências}

ALBUQUEROUE JÚNIOR, D. M. (2007) "Fragmentos do discurso cultural: por uma análise crítica do discurso sobre a cultura no Brasil." In: NUSSBAUMER, G. M. "Teorias e políticas da cultura: visões multidisciplinares." Salvador: EDUFBA.

ANTUNES DE SÁ, Ricardo (2011) "Reseña de "Como pesquisar em educação a partir da complexidade e da transdisciplinaridade?" de MORAES, M. C.; VALENTE, J. A. Revista Diálogo Educacional, Enero-Marzo, 249-253. 
AUN, J. G., Esteves de Vasconcellos, J., Coelho, S. V. (2012) "Atendimento sistêmico de

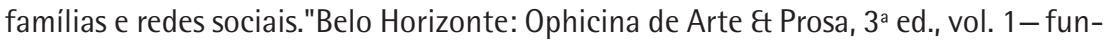
damentos teóricos e epistemológicos.

BARABÁSI, Albert-László (2009) "Linked: a nova ciência dos networks." São Paulo: Leopardo. BAYARDO, R. (2007) "Cultura e desarrollo: nuevos rumbos y más de lo mismo?" In: NUSSBAUMER, G. M. "Teorias e políticas da cultura: visões multidisciplinares." Salvador: EDUFBA. BOTELHO, I. (2007) "Políticas culturais: discutindo pressupostos" In: BURITY, J. (2007) "Cultura e desenvolvimento." In: NUSSBAUMER, G. M. "Teorias e políticas da cultura: visões multidisciplinares." Salvador: EDUFBA.

CAIUBY, Rogério (2011) "Governança Colaborativa: o poder e potencial da cocriação através das redes sociais". Symnetics, Seminário de Governança promovido pela Universidade Católica de Brasilia.

CAPRA, Fritjof (1997) "A teia da vida." São Paulo: Cultrix; Amana.

CASADESUS-MASANELL, Ramon and Ricart, Joan Enric (2009) "From Strategy to Business Models and to Tactics." University of Navarra. IESE Business School.

CHEN, Te Fu (2009) "Building a Platform of Business Model 2.0 to Creating Real Business Value with Web 2.0 for Web Information Services Industry". Department of Information Management Chang Jung Christian University. Tainan (711), Taiwan. International Journal of Electronic Business Management, Vol. 7, No. 3, pp. 168-180.

CORAZZA, Rosana Icassatti (2013) "Criatividade, inovação e economia da cultura: abordagens multidisciplinares e ferramentas analíticas." Revista Brasileira de Inovação, Campinas (SP), 12 (1), p.207-231, janeiro/junho.

CRIATIVA (2013) "Apresentação do projeto Criativa Birô." Brasília: Secretaria de Economia Criativa - Ministério da Cultura. Termo de cooperação firmado entre SEC-MinC e Fundação Universidade de Brasília.

ESTEVES DE VASCONCELLOS, J. (2013) "Pensamento sistêmico: o novo paradigma da ciência." Campinas, SP: Papirus, $10^{\text {a }}$ ed. rev. e atual.

FLEW, T. (2012) "The creative industry: culture and policy." London: Sage Publ. Ltd.

GARROSSINI, Daniela F., Caballero, Francisco S. and Maranhão, Ana C. K. (2011) "A utilização do pensamento sistêmico crítico aplicado às pesquisas comunicações." São Paulo: Congresso Mundial de Comunicação Ibero-Americana (CONFIBERCOM).

GARROSSINI, Daniela F. (2010) "As Tecnologias da Informação e Comunicação como vetores catalisadores de participação cidadã na construção de políticas públicas: o caso dos conselhos de saúde brasileiros." 285f. Tese de doutoramento (Pós-graduação em Comunicação) Universidade de Brasília, Brasília.

GIRARD, A. (1982) "Cultural industries: a handicap or a new opportunity for cultural development? Cultural Industries: a challenge for the future of culture." Paris: Unesco.

GHARAJEDAGHI, J. (2006) "Systems thinking: managing chaos and complexity: a platform for designing business architecture". BH - Elsevier, 338p., 2006.

HAKANSSON, H., Snehota, I. (1989) "No business is an island: the network concept of 
business strategy." Scand. J. Mgm. Vol. 5. No. 3, pp. 187-200.

HESMONDHALGH, D., PRAT, A. C. (2005) "Cultural industries and cultural policy. International Journal of Cultural Policy." v. 11, n. 1, p. 1-14.

HOWKINS, J. (2013) "Economia Criativa: como ganhar dinheiro com ideias criativas" São

Paulo: M.Books do Brasil.

JOHNSON, J. D. (2011) "Gestão de Redes de Conhecimento" São Paulo: editora Senac.

JOHNSON, G., Scholes, K., Whittington, R. (2007) "Explorando a Estratégia Corporativa: texto e casos". Porto Alegre: Bookman, $7^{\text {a }}$ edição.

LEMOS, A., Lévy, P. (2010) "O Futuro da Internet: em direção a uma ciberdemocracia planetária." São Paulo: Paulus.

MATURANA, Humberto R. (1999) "Ontologia da realidade." Belo Horizonte: Ed. da UFMG.

MINTZBERG, Henry (2000) "Safari de Estratégia". Editora Bookman.

MORAES, Maria C. and Valente, J. (2008) "Como pesquisar em educação a parti $r$ da complexidade e da transdisciplinaridade?" São Paulo: Paulus.

OSTERWALDER, Alexander (2011) "Business Model Generation. Inovação em Modelos de Negócios: um manual para visionários, inovadores e revolucionários". Rio de Janeiro, RJ: Alta Books.

(2004) "The Business Model Ontology a Proposition in a Design Science Approach". Diplômé postgrade en Informatique et Organisation (DPIO) de I'Ecole des HEC de I'Université de Lausanne.

PSEC (2011) "Plano da Secretaria da Economia Criativa: políticas, diretrizes e ações 2011 a 2014." Ministério da Cultura. 2a edição revisada. Acesso em 20 de janeiro de 2014. Disponivel em URL: http://www2.cultura.gov.br/site/wp-content/uploads/2012/08/ livro_web2edicao.pdf.

RESTREPO, Felipe B. and Márquez, Iván D. (2013) "La economía laranja: una oprtunidad infinita." Banco Interamericano de Desenvolvimento.

ROCHA, Thelma, et al. (2010) "Gestão dos Stakeholders: como gerenciar o relacionamento entre a empresa e seus públicos de interesse". São Paulo: Saraiva.

SEAGRIFF, T., Lord, S. (2009) "Soft Operational Research Techniques: current and future uses." Defense Science an Technology Laboratory. Operational Research Journal. Acesso em 20 de janeiro de 2014. Disponível na URL: http://www.theorsociety.com/Media/Documents/Users/CaraQuinton01011978/OriginalDocument/13_09_2011-09_48_11.pdf.

SERRA, Fernando, Torres, Maria C., Torres, A. (2003) "Administração Estratégica: conceitos, roteiro prático e casos". Rio de Janeiro: Reichmann \&t Affonso Editores.

SIERRA CABALLERO, Francisco (2013a). "Ciudadanía, tecnología y cultura". Barcelona: GEDISA.

SIERRA CABALLERO, Francisco y BENITEZ, Lucía (2013b): "Redes Sociales y Comunicación para el Desarrollo" en Marcelo Martínez; J.A. Brandariz; Xesus Lage y M. Vázquez (Coords.). Comunicación y Desarrollo, Buenos Aires: La Crujía, pp.251-271. 
SLACK, Nigel; et al. (2006) "Operations and Process Management: principles and practice for strategic impact". England: Pearson.

TARANI, P. (2011) "Emergent Creative Ecosystems: Key elements for urban renewal strategies." Aristotle University of Thessaloniki, Department of Spatial Planning and Development.

VALERIANO, D. L. (2001) "Gerenciamento Estratégico e Administração por Projetos". São Paulo: Makron Books.

VOLKERLING, M. (2001) "From cool Britannia to hot nation: creative industries policies in Europe, Canada and New Zealand." International Journal of Cultural Studies, v. 7, p. 437-455.

ZARD0, Julia et al. (2005). Incubadoras Culturais. Do negócio da Cultura à Cultura dos Negócios. Rio de Janeiro: SEBRAE/ANPROTEC. 